\title{
'Caution, this treatment is a placebo. It might work, but it might not': why emerging mechanistic evidence for placebo effects does not legitimise complementary and alternative medicines in sport
}

\author{
Chris Beedie, ${ }^{1}$ Greg Whyte, ${ }^{2}$ Andrew M Lane, ${ }^{3}$ Emma Cohen, ${ }^{4}$ \\ John Raglin, ${ }^{5}$ Phil Hurst, ${ }^{1}$ Damian Coleman, ${ }^{1}$ Abby Foad ${ }^{1}$
}

\begin{abstract}
Complementary and alternative medicines (CAM) are treatments for which either evidence is lacking, or for which evidence suggests no effect over a placebo treatment. When a non-evidence-based treatment is used alongside conventional medicine, it is considered 'complementary'. When a nonevidence-based treatment is used instead of conventional medicine, it is considered 'alternative'. Many forms of CAM have origins and/or a history of use beyond evidence-based medicine. Further, many CAM treatments are based on principles and/or evidence that are not recognised by the majority of independent scientists. When a person uses CAM and experiences an improvement in symptoms, this may be due to the placebo effect. ${ }^{1}$
\end{abstract}

\footnotetext{
${ }^{1} S c h o o l$ of Human and Life Sciences, Canterbury Christ Church University, Canterbury, Kent, UK

${ }^{2}$ Research Institute for Sport and Exercise Sciences,

Liverpool John Moores University, Liverpool, UK

${ }^{3}$ Institute of Sport, University of Wolverhampton,

Walsall, UK

${ }^{4}$ Institute of Cognitive and Evolutionary Anthropology, University of Oxford, Oxford, Oxfordshire, UK

${ }^{5}$ School of Public Health, Indiana University,

Bloomington, Indiana, USA
}

Correspondence to Dr Chris Beedie, School of Human and Life Sciences, Canterbury Christ Church University, N Holmes Rd, Canterbury, Kent CT1 1QU, UK; chris.beedie@canterbury.ac.uk
CAM is widely used in sport, often by elite athletes. One example is Michael Phelps' use of 'cupping' during the 2016 Olympics. Evidence for the effectiveness of CAM in sport has been reported in some work, but more studies have reported CAM outcomes as no better than placebo. The link between CAM and the placebo effect has been made explicit by health agencies ${ }^{1}$ and scientists. ${ }^{2}$ As a consequence, where credible causal mechanisms for apparent therapeutic effects are absent, placebo effects are often assumed.

The placebo effect was historically considered a non-specific phenomenon, but recent studies indicate numerous discrete placebo effects operating via dopamine, $^{3}$ opioid $^{4}$ and cannabinoid $^{5}$ neurotransmission. For example, placebo analgesia following preconditioning with morphine is blocked by the antagonist naloxone, but analgesia conditioned using a non-opioid drug was naloxone insensitive. Likewise, the cannabinoid receptor antagonist rimonabant had no effect on opioid-induced placebo analgesia following preconditioning with morphine, but antagonised placebo analgesia following preconditioning with the non-opioid non-steroidal anti-inflammatory drug, ketorolac.
Such connections between brain physiology and mechanistic evidence are being used as an argument for CAM. We have been researching the placebo effect in sport for some time (14 years in the case of the first author). While it is not unusual to be invited to speak at scientific conferences or to media on one's area of expertise, we now receive as many invitations to speak on the issue of CAM, and an equal volume of traffic from proponents and/or practitioners of CAM, at times congratulating us for 'legitimizing' their product or treatment.

We strongly contest this position, and propose five challenges to the idea that placebo mechanisms legitimise the use of CAM by clinicians in sports medicine/ sports physiotherapy:

1. Variability: Placebo responding is variable, both between and within athletes. ${ }^{6}$ Furthermore, most research papers report acute placebo effects, and little is known about their stability over time.

2. Negative placebo effects: The nocebo effect, a negative response related to negative expectations, is well documented. ${ }^{6}$ Rather than assuming that a CAM treatment will either result in a positive effect or no effect, practitioners must consider the possibility that administration of a placebo treatment can exert a negative effect.

3. Failure to adopt a more effective treatment: Athletes are often eager to accept at face value treatments that might expedite their return to play. Consequently, patients of practitioners who administer CAM may be denied or choose to forego potentially more effective evidence-based treatments. ${ }^{8}$ In sport, this might range from an athlete not eating sufficient fresh fruit because she is receiving sufficient vitamin $\mathrm{C}$ through supplements, to choosing CAM as opposed to conventional medicine to treat injury or illness. 
4. Ethics of deception: In light of the challenges of points 1 and 2, it is arguably unethical to knowingly advocate CAM while also assuming the likely mechanism of effect is the placebo. We acknowledge emerging evidence that open label administration of placebos can be effective. However, even in such cases, the administration of placebos may ultimately be counterproductive. There are serious ethical challenges around deception, risk and harm to patients.

5. Identification of 'headroom' mechanisms: The capacity to respond to a placebo is evidence of headroom or reserve capacity. ${ }^{6}$ Headroom is likely amenable to legitimate treatments, both physiological and psychological. Practitioners should strive to identify and capitalise on headroom through legitimate, ethical, controllable and stable treatments (eg, optimal nutrition, systematic recovery and psychological skills training).

CAM can be effective, but can also be ineffective or even harmful. Evidence is vague in both respects, but practitioners and athletes using CAM do not always recognise this. We acknowledge the distinction between lack of evidence for an effect, and evidence for the lack of an effect. In relation to the former, sports medicine researchers should seek to use robust, reliable and, where necessary, innovative methods to establish the efficacy and mechanisms of CAM treatments. In relation to the latter, sports medicine practitioners should regard non-evidence-based treatments with caution, and resist the temptation to rely on non-specific effects as a basis for prescription. If a practitioner seeks to use a treatment in order to capitalise on the placebo component of that treatment, they should do so methodically. ${ }^{9}$

In sports medicine the outcome is often more important than the mechanism. Scientific research on placebo mechanisms has yielded fascinating insights suggesting the potential efficacy and mechanisms of belief-based treatments. We anticipate that when applied systematically, such research findings enable sports medicine practitioners to deliver all treatments-CAM and conventional-more effectively. But such use of the placebo component of a treatment does not legitimise CAM per se; while it might be going too far to suggest that many CAM treatments should be labelled with the statement 'Caution: This treatment is a placebo, it may work, but it may not, it might even be counter-productive,' we argue this is most certainly the reality that practitioners should keep in mind.

Contributors All authors contributed equally to the writing of the manuscript.

Competing interests None declared

Provenance and peer review Not commissioned; externally peer reviewed.

\section{(1) OPEN ACCESS}

Open Access This is an Open Access article distributed in accordance with the Creative Commons Attribution Non Commercial (CC BY-NC 4.0) license, which permits others to distribute, remix, adapt, build upon this work non-commercially, and license their derivative works on different terms, provided the original work is properly cited and the use is non-commercial. See: http:// creativecommons.org/licenses/by-nc/4.0/

(C) Article author(s) (or their employer(s) unless otherwise stated in the text of the article) 2018. All rights reserved. No commercial use is permitted unless otherwise expressly granted.

\section{Check for updates}

To cite Beedie C, Whyte $G$, Lane AM, et al. Br J Sports Med 2018;52:817-818.

Received 3 March 2017

Revised 20 April 2017

Accepted 7 June 2017

Published Online First 19 July 2017

Br J Sports Med 2018:52:817-818.

doi:10.1136/bjsports-2017-097747

\section{REFERENCES}

1 The placebo effect and complementary and alternative medicine: national Health Service, 2016. http://www. nhs.uk/Livewell/complementary-alternative-medicine/ Pages/placebo-effect.aspx.

2 Kaptchuk TJ, Miller FG. Viewpoint: what is the best and most ethical model for the relationship between mainstream and alternative medicine: opposition, integration, or pluralism? Acad Med 2005;80:286-90.

3 Benedetti F, Frisaldi E, Carlino E, et al. Teaching neurons to respond to placebos. J Physio/ 2016;594:5647-60.

4 Benedetti F, Carlino E, Piedimonte A. Increasing uncertainty in CNS clinical trials: the role of placebo, nocebo, and Hawthorne effects. Lancet Neurol 2016;15:736-47

5 Benedetti F, Thoen W, Blanchard C, et al. Pain as a reward: changing the meaning of pain from negative to positive co-activates opioid and cannabinoid systems. Pain 2013;154:361-7.

6 Beedie CJ, Foad AJ. The placebo effect in sports performance: a brief review. Sports Med 2009;39:313-29

7 Franklyn-Miller A, Etherington J, McCrory P. Sports and exercise medicine--specialists or snake oil salesmen? $\mathrm{Br}$ J Sports Med 2011;45:83-4.

8 Smith K, Ernst E, Colquhoun D, et al. (CAM): Ethical and Policy Issues. Bioethics 2016;30:60-2.

9 Beedie C, Foad A, Hurst P. Capitalizing on the Placebo Component of Treatments. Curr Sports Med Rep 2015;14:284-7. 